\title{
O SISTEMA DE CONHECIMENTO E DE CUIDADO DOS IDOSOS EM HEMODIÁLISE CONCERNENTE ATERAPIA MEDICAMENTOSA
}

\author{
Maria Helena Lenardt ${ }^{1}$, Karina Silveira de Almeida Hammerschmidt ${ }^{2}$, Ana Paula Modesto ${ }^{3}$, Ângela Cristina da Silva Borghi ${ }^{4}$
}

RESUMO: Estudo etnográfico focado, realizado com 23 idosos em tratamento hemodialítico, usuários de uma rede de hemodiálise, na capital paranaense. O objetivo foi interpretar o sistema de conhecimento e de cuidado dos doentes idosos em hemodiálise, referente à terapia medicamentosa. Das informações emergiram 2 domínios: 1) A situação de dependência exige o apoio de outros 2) Elementos da linguagem visual e tátil são meios para identificar e organizar os medicamentos. $\mathrm{O}$ tema cultural recebeu a asserção: O idoso renal crônico e as possibilidades no alfabetismo visual. A identificação das medicações pelos idosos está fundamentada na linguagem visual e tátil, composta dos elementos básicos visuais: cor, tamanho, textura e forma das medicações. A cada meio de identificação se atribui uma grande quantidade de significados, alguns por associação, outros por vinculação arbitrária.

PALAVRAS-CHAVE: Idoso; Hemodiálise; Medicamentos; Enfermagem.

\section{THE KNOWLEDGE AND CARE SYSTEM OF ELDERLY UNDERGOING HEMODIALYSIS CONCERNING MEDICATION THERAPY}

\begin{abstract}
This is a focused ethnographic study, performed with 23 elderly subjects undergoing hemodialysis treatment, users of a hemodialysis network, in Curitiba/ Paraná State, Brazil. It aimed to interpret the knowledge and care system of elderly patients undergoing hemodialysis concerning the medication therapy. Two domains emerged from the information: 1) The situation of dependency demands others' support 2) Elements of visual and touch language are ways to identify and organize the medication. The cultural theme obtained the assertion: The elderly with chronic renal disease and the possibilities in visual alphabetization. The identification of medication by elderly subjects is grounded on visual and touch language, composed by basic visual elements: color, size, texture and shape of medication. To each way of identification is given a high amount of meanings, some by association, and others by arbitrary link.
\end{abstract}

KEY WORDS: Elderly; Hemodialysis; Medication; Nursing.

\section{EL SISTEMA DE CONOCIMIENTO Y DE CUIDADO DE LOS ANCIANOS EN HEMODIÁLISIS REFERENTE A LATERAPIA MEDICAMENTOSA}

RESUMEN: Este es un estudio del tipo etnográfico centrado, realizado con personas mayores en tratamiento hemodialítico, usuarios de una red de hemodiálisis, en la capital del Paraná, Curitiba. Se tiene como objetivo interpretar el sistema de conocimiento y de cuidado de los enfermos ancianos en hemodiálisis referente a la terapia medicamentosa. De las informaciones etnográficas, surgieron dos cuestiones centrales: 1) La situación de dependencia exige el apoyo de otras personas; 2) Elementos del lenguaje visual y táctil son medios para identificar y organizar los medicamentos. El tema cultural recebió la proposición: El anciano renal crónico y las posibilidades en alfabetismo visual. La identificación de las medicaciones por los ancianos está fundamentada en el lenguaje visual y táctil, compuesto de elementos básicos visuales: color, tamaño, textura y forma de las medicaciones. A cada medio de identificación se atribuye una gran cantidad de significados; algunos por asociación, otros por vinculación arbitraria.

PALABRAS CLAVE: Anciano; Hemodiálisis; Medicamentos; Enfermería.

${ }^{1}$ Doutora em Filosofia da Enfermagem pela Universidade Federal de Santa Catarina-UFSC. Professora Sênior do Programa de Pósgraduação em Enfermagem da Universidade Federal do Paraná-UFPR. Líder do Grupo Multiprofissional de Pesquisa sobre Idosos GMPI/UFPR.

${ }^{2}$ Mestre em Enfermagem pela UFPR. Professora da Faculdades Integradas do Brasil-UNIBRASIL-PR. Membro do GMPI.

${ }^{3}$ Mestre em Enfermagem pela UFPR. Professora da UNIBRASIL-PR. Membro do GMPI.

${ }^{4}$ Mestre em Enfermagem pela UFPR. Membro do GMPI.

Autor correspondente:

Maria Helena Lenardt

Av Cândido de Abreu, 304 - 80530-000 - Curitiba-PR

Recebido: 19/03/08

E-mail: lenardthart@hotmail.com

Aprovado: 28/03/08 


\section{INTRODUÇÃO}

O crescimento da população idosa no Brasil acarreta mudanças significativas no perfil das doenças. As que prevalecem são as doenças crônicas em geral, características das pessoas idosas. Esta situação nos leva à reflexão a respeito das condições em que esta temática é abordada. Apesar das críticas realizadas por estudiosos, o modelo de tratamento biomédico ainda tem sido a base para a formação dos diversos profissionais da saúde e para as gestões institucionais.

A biomedicina tem proporcionado avanços tecnológicos no tratamento de patologias crônicas, como a hemodiálise para os pacientes com Insuficiência Renal Crônica, aumentando a expectativa de vida. Todavia, questionamos o impacto que tais terapias têm na vida destes pacientes e se estas são realmente assimiladas por eles. Algumas fases da doença podem ser incertas, porém todas causam impactos e danos aos doentes. Cada fase tem tarefas próprias, requerendo do doente força, mudança de comportamento, de atitudes e readaptações.

O Grupo Multiprofissional de Pesquisa sobre Idosos (GMPI) desenvolve pesquisa com o idoso renal crônico. Percebemos dificuldades diversas que a situação crônica de saúde acarreta, entretanto não tínhamos ainda elaborado uma proposta ampla, um diagnóstico efetivo que permitisse elaborar um programa de educação à saúde "para" e "com" os doentes renais crônicos.

Pelas experiências profissionais do grupo, fruto de observações empíricas, percebemos que no cotidiano do paciente renal crônico em terapia hemodialítica é visível a dificuldade que este apresenta para assimilar as orientações de cuidado quanto à medicação coadjuvante à terapia. Para a efetividade do tratamento faz-se necessário que o paciente tenha cuidados com os seguintes medicamentos: a eritropoetina, o calcitriol, o sacarato de hidróxido de ferro e o carbonato de cálcio.

Nós, profissionais enfermeiros, precisamos compreender a lógica de cuidados do doente idoso e conhecer a linguagem utilizada por ele para que se sinta compreendido, protegido e venha a participar efetivamente das orientações de cuidados, referentes aos medicamentos que precisa ingerir diariamente e ou freqüentemente.

A proposta de educação à saúde está alicerçada na relação dialógica entre profissionais de saúde e idosos, e não na aquisição do saber em si como resultado final da instrução unilateral. O programa de educação à saúde deve ter efeito cumulativo, pois acreditamos que a capacidade de aprender do doente envolvido aumenta conforme novos desafios vão sendo enfrentados no seu cotidiano. O programa objetiva reforçar a natureza do ser humano (doente e profissional) como um sistema aberto, disponível e flexível à mudança durante toda a vida. Respeitando a linguagem, o sistema de conhecimento e a história de vida dos doentes, podemos levá-los a tomar consciência da realidade dos seus cuidados. Os conteúdos a serem desenvolvidos não podem ser desvinculados da realidade em que os doentes estão inseridos. O "diálogo libertador" é a tônica e não o "monólogo opressivo"(1-2)

Diante do exposto temos como objetivo: interpretar o sistema de conhecimento e de cuidado dos doentes idosos em hemodiálise, referente à terapia medicamentosa.

\section{METODOLOGIA}

Trata-se de uma pesquisa etnográfica focada, de caráter antropológico interpretativista ${ }^{(3-6)}$. A etnografia se constitui na metodologia do estudo e tem por objetivo conhecer o ponto de vista de outro (emic), sendo o conceito de cultura a chave deste processo.

Utilizamos neste estudo o seguinte conceito de cultura:

cultura é um padrão de significados transmitidos historicamente, incorporado em símbolos, um sistema de concepções herdadas expressas em formas simbólicas por meio das quais os homens comunicam, perpetuam e desenvolvem seu conhecimento e suas atividades em relação à vida ${ }^{(5 ; 103)}$.

A etnografia focada ${ }^{(7)}$ é aquela que se utiliza um tempo limitado para o estudo de uma comunidade ou organização. Os informantes-chaves são, em menor número, normalmente aqueles que possuem mais conhecimento e experiência sobre o problema a ser estudado.

\section{Situação social e informantes}

A pesquisa foi realizada em uma rede de hemodiálise que presta serviços ao Sistema Único de Saúde e aos convênios particulares na grande Curitiba, no período de março a agosto de 2004. Trata-se de uma situação social na qual há atores e atividades que 
se localizam em diferentes cenas culturais, especificamente na sala de hemodiálise, nos corredores, na sala de espera, nas salas de consulta da enfermagem, da nutrição, do médico e na sala de lanche para os doentes. Nestes cenários observamos com mais freqüência o contato do doente renal crônico com a equipe de enfermagem.

Adotamos a definição de idoso conforme a Lei $\mathrm{n}^{\circ}$ 8842/94 que dispõe sobre a Política Nacional do Idoso $^{(8: 12277)}$ : "o idoso é aquele que conta igual ou mais de 60 anos".

Os informantes-chaves foram 23 doentes idosos renais crônicos que realizam hemodiálise nas clínicas de doenças renais, durante o turno da tarde. As (os) enfermeiras (os), técnicos e auxiliares da equipe de enfermagem participaram como "atores do cenário [...]"(9:32), para os quais eventualmente solicitamos algumas informações sobre a situação observada”.

\section{Coleta das informações}

Utilizamos a observação participante e a entrevista etnográfica como técnicas de coleta de dados. Durante a observação participante, seguimos as etapas preconizadas por Spradley ${ }^{(10)}$ para a coleta de dados.

$O$ roteiro da entrevista etnográfica seguiu as questões: qual; como é e por que desenvolve o sistema de conhecimento e de cuidados referente à terapia medicamentosa no tratamento hemodialítico? São questões descritivas, estruturais e de contraste.

As questões descritivas foram utilizadas durante todo o processo de observação descritiva, focalizada e seletiva. Seu objetivo é expandir a explicação dos participantes constituindo-se na base da entrevista, o que permite o conhecimento do modo como os idosos "vêem" a medicação.

As questões estruturais permitiram compreender como os idosos organizam aquilo que sabem. Elas complementaram e ampliaram os dados descritivos e permitiram o conhecimento da organização sistemática da cultura de cuidados referente à medicação. Utilizaram-se também as questões contraste que têm como finalidade comparar para mostrar as diferenças. Foram formuladas à medida que o pesquisador notou as diferenças específicas na forma que o informante (idoso) descreveu a simbologia dos cuidados com a medicação.

Inicialmente realizamos observações gerais do cenário e descrevemos as características físicas da unidade de hemodiálise. Neste momento também participamos de um treinamento na clínica, referente ao processo de hemodiálise, o qual visava nossa adaptação naquele ambiente e ao mesmo tempo nossa interação com os atores do estudo. Caracterizamos as visitas de médicos, enfermeiros, nutricionistas, assistentes sociais identificando a relação interativa existente entre estes profissionais e os idosos.

Após este primeiro contato com o cenário como um todo, passamos a observar somente os atores que interessavam para o estudo: os 23 idosos, do turno da tarde (período da nossa permanência), da clínica de hemodiálise.

Registramos o comportamento dos idosos, com orientação para o que eles fazem e o que sabem (observando suas conversas com outras pessoas). Durante as observações e registros acompanhamos a trajetória dos idosos a partir da chegada na clínica: como e com quem chegavam, de que modo apresentavam as expressões faciais, o que faziam quando adentravam a clínica, o que falavam com os companheiros de terapia e com os profissionais de saúde e funcionários.

\section{Registros e análises das informações}

As observações gerais, focalizadas e as entrevistas etnográficas foram registradas num diário de campo na forma de linguagem descritiva, as quais foram revisadas periodicamente com o objetivo de completá-las e reorientar a observação e a investigação. As informações foram submetidas às analises de domínios, taxonômicas e temáticas ${ }^{(9-11)}$.

Foi procedida a leitura cuidadosa das descrições, elaboradas a partir dos registros de campo, na procura de domínios culturais. Foram assinalados e, a seguir, agrupados às correspondentes relações semânticas. Após análise de domínios, procedemos à análise taxonômica, agrupamos o conjunto de categorias organizadas sobre a base de uma só relação semântica, que demonstra as relações de todos os termos incluídos do domínio. Desta maneira, a análise taxonômica indicou a forma como os subconjuntos estão relacionados como um todo, mostrando os diferentes níveis que existem dentro de cada um.

Realizamos a descoberta dos temas mediante o processo de imersão intelectual. Estabelecemos as relações que se processaram entre os domínios, tentando formar um conjunto que representou o pensamento dos atores/informantes acerca dos 
conceitos que permeiam o conhecimento e os cuidados referentes aos medicamentos.

\section{Aspectos éticos}

Respeitamos os preceitos éticos de participação voluntária, esclarecida e consentida segundo Resolução $196 / 96^{(12)}$ que rege pesquisas em seres humanos. Inicialmente tomamos providências para requerer a aprovação do projeto na rede de hemodiálise e entrada na Comissão de Ética Setorial da UFPR. Foi aprovado respectivamente em 11 e 15 de agosto de 2005.

Os atores que fazem parte do estudo a partir das observações e questionamentos foram consultados e esclarecidos. Foi garantido o direito de desistirem da participação, de mantermos sigilo das informações prestadas, assim como de completo anonimato.

\section{RESULTADOS}

Domínio Cultural 1 - A situação de dependência exige o apoio de outros.

As salas de lanche são espaços de interação entre os doentes, no entanto constatamos que eles conversam em poucos momentos. Os idosos em suas falas são bastante lacônicos e aparentam intenso desânimo. Os diálogos mantidos estão relacionados, predominantemente, a própria doença e ao estado de saúde daquele dia.

Nas idades mais avançadas as reações emocionais tendem a assumir a forma depressiva ${ }^{(13)}$. Constatamos este fato quando os idosos adentram a clínica de hemodiálise. Em resposta aos questionamentos são bastante lacônicos e durante as brincadeiras desenvolvidas pela equipe de enfermagem raramente sorriem.

Não bastando os problemas relacionados ao processo de envelhecimento, a existência de uma doença crônica acarreta profundas modificações no modo de vida dos idosos em diversos contextos, como o social e o econômico.

Ao adentrar a clínica os idosos mantém os mesmos hábitos diariamente, alguns tomam lanche, enquanto outros esperam ansiosamente seu lugar na cadeira (própria para hemodiálise), para iniciarem a sessão de hemodiálise. Esta ansiedade ou inquietação faz parte do quadro melancólico que os idosos em tratamento hemodialítico apresentam, conforme se destaca (13:112): "além da depressão, a ansiedade é um elemento conspícuo do estado afetivo; [...] a ansiedade exprime-se por uma inquietação e agitação”.

Dos 23 idosos 10 deles (43\%) chegaram à clínica de carro, acompanhados por algum membro da família; 10 idosos, (43\%) em transporte fornecido pela prefeitura dos municípios; 2 (9\%) compartilham automóvel com colega de terapia (um deles paga mensalmente ao colega determinado valor por este transporte); apenas 1 (5\%) dirige o próprio veículo.

Os dados apresentados no domínio cultural acima revelam a dependência dos idosos quanto ao meio de transporte para chegar à clínica de hemodiálise. A maioria deles depende de familiares ou do transporte da prefeitura do município onde mora. Isto representa e é conseqüência da dependência financeira e física. A impossibilidade física para dirigir também fica evidente, à medida que a acuidade visual declina progressivamente e os membros superiores estão fragilizados devido à fístula arteriovenosa.

Os idosos que se encontram na situação de “dependência” dos familiares para chegar à clínica de hemodiálise alegaram sentir-se chateados, por provocarem "incômodo" ao familiar que precisa assumir o transporte deles. Esta situação foi descrita nos seguintes discursos:

Hoje era um dia que eu não vinha fazer hemodiálise [...] nos dias assim parece que a gente atrapalha todo mundo, parece que o caminho até aqui fica longe. Quando a gente fica doente, atrapalha todo mundo [...]( LS. 70 anos).

Até que a hemodiálise não dá problema, mas o incômodo que provoco lá em casa para me trazerem [...]. Poderia até estar morando sozinho (EO. 69 anos).

O transporte realizado pela prefeitura é oferecido gratuitamente para os doentes que realizam hemodiálise. Algumas vezes este tipo de transporte traz transtornos para os idosos que se utilizam dele, como chegar atrasado em algumas sessões de hemodiálise, acontecimentos que os deixa bastante irritados.

A vida do portador de insuficiência renal crônica gira em torno de sua doença e acarreta muitas dificuldades e decepções para estes doentes, principalmente para aqueles que ainda precisam trabalhar. A valorização da força física pelos trabalhadores e sua identificação com o conceito de saúde é uma representação que oferece vários significados $^{(14)}$. 
Para os idosos em hemodiálise a doença significa a impossibilidade de trabalhar e a saúde é representada pela capacidade de trabalho. Esse significado comporta uma "ambigüidade fundamental, uma vez que, se por um lado o trabalho requer saúde, por outro ele é percebido como fonte de desgaste físico e de doença”(14). Esta situação foi descrita nos seguintes relatos:

Bom não estou, senão não estava aqui, estava na roça (EF. 62 anos).

Quando fiquei doente tive que parar de trabalhar, porque eu trabalhava no pesado, carregava muita madeira pesada de um lado para outro, e com esse negócio no braço não posso mais carregar nada pesado[...] (AS. 62 anos).

A baixa escolaridade dos idosos é dado significativo e origina condições e tipos de trabalho (lavradores, pedreiros, carpinteiros) bastante difíceis de serem mantidos após o diagnóstico de um agravo à saúde como a Insuficiência Renal Crônica. Dos idosos pesquisados, $77 \%$ deles possuíam apenas o ensino fundamental incompleto e $23 \%$ eram analfabetos. Isto chama a atenção para o nível de compreensão do tratamento e do modo de se cuidar destes idosos. Como muitos deles não sabem ler e escrever, dependem de familiares para a ingestão da medicação e desenvolvem saberes e práticas que possibilitam, ao seu modo, cuidar-se.

A compreensão do idoso a respeito do medicamento está diretamente relacionada ao grau de escolaridade deste, ao modo como ingeri-lo e até mesmo ao modo de identificá-lo. A seguir, alguns fragmentos de discurso que exemplificam:

Tomo um remédio que tem pozinho dentro, com uma pontinha vermelha, e outra branca. Este tomo em jejum. Ele é uma capinha (AA. 78 anos).

Tomo um comprimido cor-de-rosa que parece uma gelatina. 2 por dia pela manhã (MC. 61 anos).

Os entendimentos dos idosos deste estudo a respeito da medicação (dosagem/horários para ingestão) são insuficientes para realizar o cuidado adequado conforme as recomendações profissionais. Para aqueles que moram com familiares, estes surgem como fator decisivo no sistema de conhecimento e de cuidado com a medicação. O familiar é parte importante no processo de identificação e organização da terapêutica. Os relatos seguintes ilustram:

A minha filha separa os remédios para mim, ela sabe os horários que eu tomo, separa pra mim e me dá todos os remédios (IU. 66 anos).

Quando a gente tem quem separa os remédios acaba nem tomando conhecimento dos remédios que toma (SRM. 70 anos).

Domínio cultural 2 - Elementos da linguagem visual e tátil são meios para identificar e organizar os medicamentos.

Os saberes e práticas desenvolvidas pelos idosos para a utilização dos medicamentos estão baseados na linguagem visual. A identificação das medicações, como verificamos a seguir, é realizada pelos idosos por meio da forma, cor, textura e dimensão dos comprimidos, ampolas e embalagens:

Tomo aquele comprimido rosa, bem mole, é sem caixa. Tem um que é maior, mas este é pequeno (AJ. 63 anos).

Aquele branco só quando minha filha ajeita, esqueço que tem dois clarinhos, assim fica difícil (EHS. 70 anos).

Podemos verificar que o elemento cor é muito significativo na identificação da medicação. A

cor tem afinidade com as emoções e está de fato impregnada de informação, e é uma das mais penetrantes experiências visuais que todos temos em comum ${ }^{(15: 64)}$.

Segundo o autor (15:64) "cada uma das cores tem inúmeros significados associativos e simbólicos". Observamos que os idosos atribuem significados para as cores dos comprimidos, determinando por meio da cor a composição da identificação e da sua finalidade.

Constatamos que os idosos utilizam também o elemento básico visual forma, para distinguir os remédios que fazem uso. As características da forma das embalagens são estruturas que o idoso memoriza com facilidade:

[...] o da caixa quadrada menor tenho que tomar todos os dias. Depois que busco dentro do saquinho plástico passo para a caixa quadrada, assim não 
tem erro (M.C., 61 anos).

Cada uma das

formas tem suas características específicas e a cada uma se atribui uma grande quantidade de significados, algumas por associação, outros por vinculação arbitrária, e outros, ainda, através de nossas próprias percepções psicológicas e fisiológicas ${ }^{(15: 57-8)}$.

A textura da mesma forma é um elemento importante na identificação da medicação para os idosos. Já que a apreciação e reconhecimento da textura pode ocorrer tanto através do tato quanto da visão ou mediante a combinação de ambos:

Um dos remédios branco, grande, tomo no almoço. É mais duro e desce rasgando.Tomo com bastante água. O pequeno só de pegar amolece e quebra [...] (AJC. 63 anos).

A dimensão foi apontada em termos comparativos. A comparação entre os tamanhos dos comprimidos como fim de identificação é freqüente pelos idosos, pois a maioria deles utiliza vários medicamentos em virtude de patologias associadas à doença renal crônica. O significado das coisas se baseia naquilo que vemos e tocamos. Essa afirmativa é fundamental para os idosos e fator para a sobrevivência dos cuidados com a medicação.

Tema cultural - O idoso renal crônico e as possibilidades no alfabetismo visual

Alguns acontecimentos provocam modificações superficiais no cotidiano dos homens, outros geram verdadeiras mudanças. Uns passam quase despercebidos para a maior parte das pessoas, outros mudam o rumo de suas vidas. Dentre os acontecimentos que provocam significativas mudanças está a doença, que atua com mais intensidade quando marcada pela cronicidade e velhice.

Os sofrimentos pelos quais perpassam os idosos acometidos por doenças crônicas em nosso país são contínuos, progressivos e cruciais, ocasionados pela própria doença e pelo processo de exclusão que vive 0 idoso. Como forma de minimizar esse cruel processo, eles tentam encontrar caminhos de menores sofrimentos, abrindo-se para eles mesmos, escutando-se, abrindose para as suas próprias possibilidades diante da vida.

As lacunas entre nós profissionais, que somos letrados, e os idosos, com conhecimentos fundamentados no alfabetismo visual, definem as verdadeiras fronteiras da compreensão das coisas. Quando negamos por completo a realidade dos próprios conhecimentos e possibilidades dos idosos durante as situações de cuidados, isto equivale a nos isolar desse conhecimento e das possibilidades de relação e interação entre nós e eles. Segundo autor, ${ }^{(6: 76)}$ "obscurecer essa lacuna e assimetria [...], relegandoas ao campo da diferença passível de ser ignorada, da mera dessemelhança, é etnocentrismo [...]”. Devese considerar que há modos de vida bons para um grupo e que jamais serviriam para outro. Os estudos de grupos humanos vêm demonstrando que, embora existam expressivas diferenças, elas não são necessariamente inferiores. Precisamos entender que os idosos com baixo nível de escolaridade não são superiores e não são inferiores, mas diferentes, com menores possibilidades num amplo sentido.

O caminho das possibilidades de melhor qualidade de vida para os idosos deste estudo é a sabedoria que armazenaram ao longo dos anos e que poderá ser a vantagem para minimizar as limitações da doença, do processo de envelhecimento, da condição sócio-econômica e da carência de cuidados. Nesses idosos, encontramos como resultado da pesquisa etnográfica a sabedoria da cultura popular que advém principalmente das relações de parentesco com familiares e vizinhos, impregnada pela baixa escolaridade e pelo baixo nível sócio-econômico.

Somos um país que está se tornando grisalho com o aumento da expectativa de vida, entretanto nos deparamos com a sofrível qualidade de vida que eles possuem. Defrontamos não somente com um perfil de baixa renda e escolaridade nos idosos pesquisados, mas com o despreparo da estrutura social para se adequar e fornecer qualidade de vida a eles com o que lhes resta de possibilidades. Assim, o sofrimento dos nossos idosos surge não somente diante de suas limitações, mas também diante de um país que ainda se prepara para abrigá-los e cuidá-los.

Tentamos ouvir a linguagem da sabedoria dos idosos, o seu sistema de conhecimento e de cuidados concernentes à medicação da qual fazem uso. A linguagem predominante é aquela da cultura popular que não atingiu a alfabetização da escrita. Encaramos este idoso como possuidor de bases do alfabetismo visual, aguçado, talvez, pela condição de analfabeto na escrita e muitas restrições na comunicação verbal.

Este idoso é capaz de visualizar, capaz de formar imagens mentais, fenômeno que descreve a fantástica capacidade do ser humano de se lembrar de 
características visuais em determinada situação. Sem dúvida a linguagem verbal tem sido uma poderosa ferramenta de comunicação, mas não se basta nas orientações de cuidados que nós profissionais levamos a efeito com os idosos.

Percebemos que o processo de criar imagens mentais para o idoso analfabeto de escrita contribui, muitas vezes, para a busca de soluções práticas durante as orientações de cuidados. Contudo, ao trabalhar com a linguagem visual alerta-se para um caminho de possíveis resultados imprevisíveis: "a visão é natural até certo ponto, mas a eficácia, em ambos os níveis, só pode ser alcançada através do estudo"(15: ${ }^{65)}$ da percepção humana.

O modo visual, porém, não oferece sistemas estruturais definitivos e absolutos. Não há regras absolutas: o que existe é um alto grau de compreensão do que vai acontecer em termos de significado, se fizermos determinadas ordenações das partes que nos permitam organizar e orquestrar os meios visuais. Muitos critérios para o entendimento do significado na forma visual decorrem da investigação do processo de percepção humana. Na criação de mensagens visuais, o significado não se encontra apenas nos efeitos cumulativos da disposição dos elementos básicos, mas também no mecanismo perceptivo universalmente compartilhado pelo organismo humano ${ }^{(15)}$.

O idoso manifestou seu sistema de conhecimento referente aos medicamentos por meio de elementos básicos visuais: a linha, a cor, a forma, a textura, a dimensão. Esses constituem ingredientes básicos com os quais contamos para o desenvolvimento do pensamento e da comunicação visual dos idosos pesquisados, pois apresentam o dramático potencial de transmitir informações de forma fácil e direta, mensagens que podem ser apreendidas com naturalidade por qualquer idoso capaz de ver.

\section{CONSIDERAÇÕES FINAIS}

Os resultados da pesquisa etnográfica apontaram atividades que necessariamente apresentam restrição do potencial em termos conceituais e estéticos, pois a linguagem visual é predominante na realidade dos idosos deste estudo. Para analisar e compreender a estrutura total desta linguagem visual sugere-se a utilização da fotografia como recurso pedagógico na educação em saúde para idosos, como mais apropriada e próxima ao sistema de conhecimento identificado no estudo.
Espera-se que o sistema de conhecimento e de cuidados destes idosos com a terapia medicamentosa, advindos principalmente da cultura popular que emerge do contexto educacional, social, econômico, sejam necessariamente provisórios, pois deseja-se interagir com estes em todas as possibilidades, na linguagem da leitura, da fala, da escrita e na visual no intuito de modificar comportamentos. Acredita-se que este estudo poderá fornecer uma pequena base epistêmica, preliminar, para futuras investigações relacionadas ao sistema de conhecimento e de cuidados dos idosos referente à medicação.

Acredita-se que todas as culturas, por mais rudimentares que sejam, são dotadas de estrutura, possuem no seu interior coerência e sentido. As práticas culturais que rejeitamos possuem uma lógica no interior das sociedades que as adotam, são funcionais para sua existência. O homem "estabelece pautas simbólicas para marcar os limites do comportamento e guiá-lo ao longo dos caminhos previsíveis"(5:57-8).

Apesar dos idosos estarem condicionados pela cultura popular, há possibilidades em alterar comportamentos, principalmente aqueles que colocam em risco a sua saúde. Estas mudanças implicam na utilização de estratégias que condicionem a modificação, mediante as possibilidades que possuem e frente à criação de espaços nos quais propiciem a construção e desenvolvimento das transformações.

É indispensável para os profissionais envolvidos no cuidado destes idosos, não circunscreverem o sistema de conhecimento e de cuidados próprios como verdades absolutas. Um esforço "extremamente sério, quase severo, de entendimento se faz necessário para estabelecer relações, lidar com o conflito entre nossa maneira profissional de olhar as coisas e o modo como o idoso olha"(16:23).

As estratégias devem estar alicerçadas nas possibilidades do sistema de cuidados dos idosos. Entender e respeitar o sistema de conhecimento dos idosos e ao mesmo tempo apreciar as variações individuais trazem elementos substanciais para a base de um cuidado efetivo na terapia medicamentosa.

\section{REFERÊNCIAS}

1. Freire P. Extensão ou comunicação. $10^{\mathrm{a}}$ ed. Rio de Janeiro: Paz e Terra; 1992.

2. Freire P. Pedagogia da autonomia: saberes necessários à prática educativa. 9a ed. São Paulo: Paz e Terra; 1998. 
3. Geertz CA. Local knowledge: further essays in interpretative anthropology. New York: Basic Books; 1983.

4. Geertz CA. Works and lives: the anthropologist as author. Stanford: University Press; 1988.

5. Geertz CA. Interpretação das culturas. Rio de Janeiro: LTC; 1989.

6. Geertz CA. Nova luz sobre a antropologia. Rio de Janeiro: Jorge Zahar; 2001.

7. Müeckle MA. On the evaluation of ethnographies. In: Morse J. Critical usues in qualitative research methods. Thousand Oaks: Sage; 1994.

8. Brasil. Decreto n. 1948, de 03 de julho de 1996. Regulamenta a Lei 8.842, sancionada em 4 de julho de 1994, a qual "dispõe sobre a Política Nacional do Idoso e dá outras providências.Brasília: Diário Oficial da República Federal do Brasil, v.134, n.128, p.12277-9, 03 de junho. Sessão 1(b).

9. Spradley JP. The ethnographic interview. New York: Rinehart and Winston; 1979.

10. Spradley JP. Participant observation. Orlando: Holt, Rinehart and Winston; 1980.

11. Spradley JP, McCurdy, DW. The cultural experience: ethonography in complex society. Chigaco: SRA; 1972.

12. Ministério da Saúde (BR). Conselho Nacional de Saúde. Diretrizes e normas regulamentadoras de pesquisa envolvendo seres humanos. Resolução n. ${ }^{0}$ 196, 10 de outubro de 1996. Brasília; 1996.

13. Araújo FAC Sonho e melancolia (involutiva). Arq Geriat Gerontol.1996; 1(1): 45-9.

14. Queiroz MS., Canesqui AM. A antropologia da medicina: uma revisão teórica. Rev Saúde Públ. 1986;20(2):152-64.

15. Dondis DA. Sintaxe da linguagem visual. $2^{\mathrm{a}}$ ed. São Paulo: Martins Fontes; 1997.

16. Lenardt MH, Michaltuch DO, Kuznier TP, Santos VL. O cuidado de si do idoso como instrumento de trabalho no processo de cuidar. Cogitare Enferm. 2005 Jan/ Abr;10(1):16-25. 